\title{
Encapsulation and Delivery of Neutrophic Proteins and Hydrophobic Agents Using PMOXA-PDMS-PMOXA Triblock Polymersomes
}

\author{
Alexandre Moquin, ${ }^{\dagger} \mathrm{Jeff}_{\mathrm{Ji}}^{\dagger},^{\dagger}$ Kevin Neibert, $^{\dagger}$ Françoise M. Winnik, $^{\dagger, \S, \|_{\odot}}$ and Dusica Maysinger ${ }^{*}, \dagger \odot$ \\ ${ }^{\dagger}$ Department of Pharmacology and Therapeutics, Faculty of Medicine, McGill University, 3655 Promenade Sir-William-Osler, H3G \\ $1 Y 6$ Montreal, Québec, Canada \\ "Département de Chimie, Université de Montréal, CP 6128 Succursale Centre-Ville, H3C 3J7 Montréal, Québec, Canada \\ ${ }^{\S}$ International Center for Materials Nanoarchitectonics (MANA), National Institute for Materials Science (NIMS), 1-1 Namiki, \\ 305-0044 Tsukuba, Ibaraki, Japan \\ "Department of Chemistry, University of Helsinki, FI-00014 Helsinki, Finland
}

Supporting Information

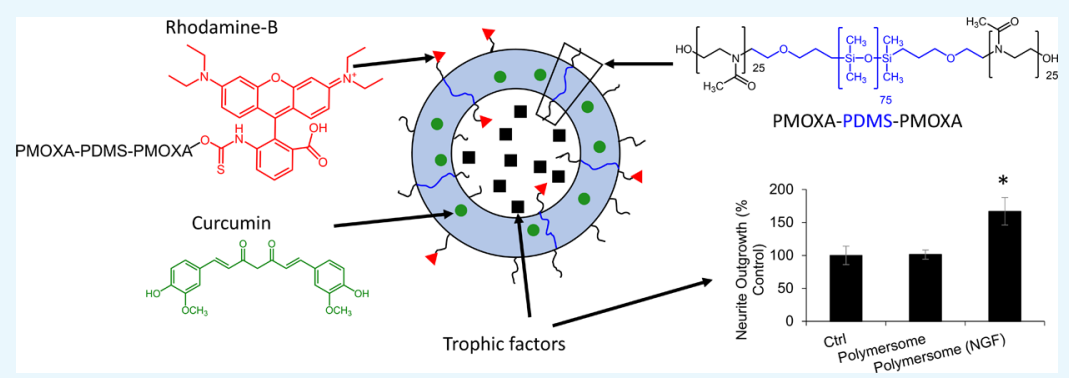

ABSTRACT: Polymersomes are attractive nanocarriers for hydrophilic and lipophilic drugs; they are more stable than liposomes, tunable, and relatively easy to prepare. The copolymer composition and molar mass are critical features that determine the physicochemical properties of the polymersomes including the rate of drug release. We used the triblockcopolymer, poly(2-methyl-2-oxazoline)-block-poly-(dimethysiloxane)-block-poly(2-methyl-2-oxazoline) (PMOXA-PDMSPMOXA), to form amphipathic polymersomes capable of loading proteins and small hydrophobic agents. The selected agents were unstable neurotrophins (nerve growth factor and brain-derived neurotrophic factor), a large protein CD109, and the fluorescent drug curcumin. We prepared, characterized, and tested polymersomes loaded with selected agents in 2D and 3D biological models. Curcumin-loaded and rhodamine-bound PMOXA-PDMS-PMOXA polymersomes were used to visualize them inside cells. N-Methyl-D-aspartate receptor (NMDAR) agonists and antagonists were also covalently attached to the surface of polymersomes for targeting neurons. Labeled and unlabeled polymersomes with or without loaded agents were characterized using dynamic light scattering (DLS), UV-vis fluorescence spectroscopy, and asymmetrical flow field-flow fractionation $\left(\mathrm{AF}_{4}\right)$. Polymersomes were imaged and tested for biological activity in human and murine fibroblasts, murine macrophages, primary murine dorsal root ganglia, and murine hippocampal cultures. Polymersomes were rapidly internalized and there was a clear intracellular co-localization of the fluorescent drug (curcumin) with the fluorescent rhodamine-labeled polymersomes. Polymersomes containing CD109, a glycosylphosphatidylinositol-anchored protein, promoted cell migration in the model of wound healing. Nerve growth factor-loaded polymersomes effectively enhanced neurite outgrowth in dissociated and explanted dorsal root ganglia. Brain-derived neurotrophic factor increased dendritic spine density in serum-deprived hippocampal slice cultures. NMDAR agonist- and antagonist-functionalized polymersomes targeted selectively neurons over glial cells in mixed cultures. Collectively, the study reveals the successful incorporation into polymersomes of biologically active trophic factors and small hydrophilic agents that retain their biological activity in vitro, as demonstrated in selected central and peripheral tissue models.

\section{INTRODUCTION}

In living cells, many cellular functions are performed by nanometer-scale vesicles. ${ }^{1,2}$ Biological vesicles store substances, such as neurotransmitters, and control the extent of their release. $^{3-5}$ There is a current interest to use cellular vesicles, most notably exosomes, ${ }^{6-8}$ as carriers to deliver drugs, in view of their compatibility with cells and organs. Still, in the context of therapeutic carriers, biological vesicles have few limitations such as complex composition, limited stability, and modest loading of either lipophilic drugs or proteins. ${ }^{9}$ Synthetic

Received: September 7, 2018

Accepted: October 11, 2018

Published: October 23, 2018 
vesicles constructed with amphiphilic block copolymers, or polymersomes, are designed to overcome these limitations. ${ }^{10,11}$ They accommodate lipophilic compounds in their membrane and hydrophilic agents in their aqueous core. ${ }^{11-15}$ Like most nanocarriers, polymersomes, were primarily developed as carriers for anticancer agents. ${ }^{16-20}$ Stimulus-controlled drug delivery from polymersomes has been demonstrated as well, using triggers such as changes in $\mathrm{pH}$ or in temperature. . $^{10,20-24}$ There is such a diversity in polymer composition, structure, and functionality, that it is possible to design polymersomes adjusted to complement the properties of their cargo, from small synthetic molecules and peptides to large biological compounds such as proteins. ${ }^{25}$ We opted for self-assembling polymersomes made of the triblock copolymer, poly (2-methyl2-oxazoline)-block-poly-(dimethysiloxane)-block-poly(2-methyl-2-oxazoline) (PMOXA-PDMS-PMOXA), as their suitability for protein protection and transport was reported earlier. $^{26}$ Moreover, PMOXA, which is known for its nonfouling properties, provides stealth properties to the polymersomes. $^{27-29}$

We assessed polymersomes in biological models in 2D ("wound in the dish") and 3D explanted ganglia ${ }^{30}$ with more complex structures consisting of different cell populations. Under normal conditions, wound healing occurs through a multistage pathway that includes coagulation, inflammation, formation of granulation tissue, and remodeling. ${ }^{31-34}$ In severe or chronic pathological conditions, the healing process is locked in a state of chronic inflammation due to the presence of cytokines, chemokines, and reactive oxygen species in the milieu, that cause further damage related to oxidative stress. Therapeutic agents currently used for wound healing include agents promoting epithelization and antibiotics to eliminate infection at the site of injury. ${ }^{35,36}$ In pathologies such as diabetes, wound healing is impaired because of inadequate trophic support due to peripheral nerve injury. This repair requires trophic support in the form of nerve growth factor (NGF), brain-derived neurotrophic factor (BDNF), and NT3 normally supplied and retrogradely transported from the target tissues (skin and muscles) to the soma [dorsal root ganglia (DRG)]. NGF promotes axonal growth in both the peripheral and central nervous system. ${ }^{37-40}$ NGF binds to the nerve terminal and is retrogradely transported to the cell body, where it signals the transcription factor CREB to upregulate prosurvival genes. ${ }^{40} \mathrm{BDNF}$ is a $27 \mathrm{kDa}$ protein, which when excreted by microglia has been reported to increase neuronal survival. ${ }^{41-43}$ NGF and BDNF exhibit wound healing properties and are excellent candidates for nerve repair.

Other agents have been proposed as therapeutics for wound healing. Anti-oxidants, such as curcumin (diferuoylmethane), a natural small hydrophobic and unstable molecule, have been shown in phase 1 clinical trials to have high safety and wound healing properties. ${ }^{4-47}$ CD109 is a membrane protein, approximately $180 \mathrm{kDa}$, which binds to TGF- $\beta$ and represses TGF- $\beta$ signaling in human keratinocytes. ${ }^{48-51}$ Because curcumin and proteins such as CD109, NGF, and BDNF are unstable in biological environments, ${ }^{52,53}$ it is advantageous to incorporate them into nanocarriers to protect them from hydrolytic and enzymatic cleavage to reach the site of injury.

We investigated the safety and effectiveness of PMOXAPDMS-PMOXA triblock copolymer in delivering small hydrophobic molecules such as curcumin and larger hydrophilic proteins such as NGF and BDNF to promote wound healing and neural regeneration. We characterized the polymersome structure and drug loading using transmissionelectron microscopy (TEM), asymmetrical flow field-flow fractionation, UV spectroscopy, and dynamic light scattering (DLS), while drug release was monitored using a dialysis bag method. In addition, drug-loaded polymersomes were tested in both $2 \mathrm{D}$ scratch assays as well as $3 \mathrm{D}$ organotypic cultures. This study demonstrates that PMOXA-PDMS-PMOXA is nontoxic and effective in delivering proteins and small molecules to macrophages, fibroblasts, and neurons of the DRG and in the hippocampus.

\section{RESULTS AND DISCUSSION}

To protect the photolabile curcumin and the labile proteins (CD109, NGF, and BDNF) used in this study against harsh environments, we incorporated them into PMOXA-PDMSPMOXA polymersomes. ${ }^{54}$ The triblock PMOXA-PDMSPMOXA copolymer was selected in view of its known chemical stability and low toxicity. ${ }^{26,55}$ It was synthesized following a known procedure, $^{26}$ shown schematically in Figure S1. The chemical structure of the copolymer and the synthetic intermediates was ascertained by ${ }^{1} \mathrm{H}$ NMR (Figure S2) and ${ }^{19} \mathrm{~F}$ NMR spectroscopy (Figure S3). The molar mass of the copolymer $\left(M_{\mathrm{n}}=9.84 \mathrm{kDa}\right)$ was determined by ${ }^{1} \mathrm{H}$ NMR spectroscopy and gel permeation chromatography (GPC, $M_{\mathrm{n}}=$ $\left.8.8 \mathrm{kDa}, M_{\mathrm{w}} / M_{\mathrm{n}}=1.4\right)$. The chemical structure of PMOXAPDMS-PMOXA is shown in Figure 1A, where the subscripts 25 and 75 represent, respectively, the numbers of MOXA and DMS units in the blocks, as determined from the ${ }^{1} \mathrm{H}$ NMR spectrum of the copolymer.

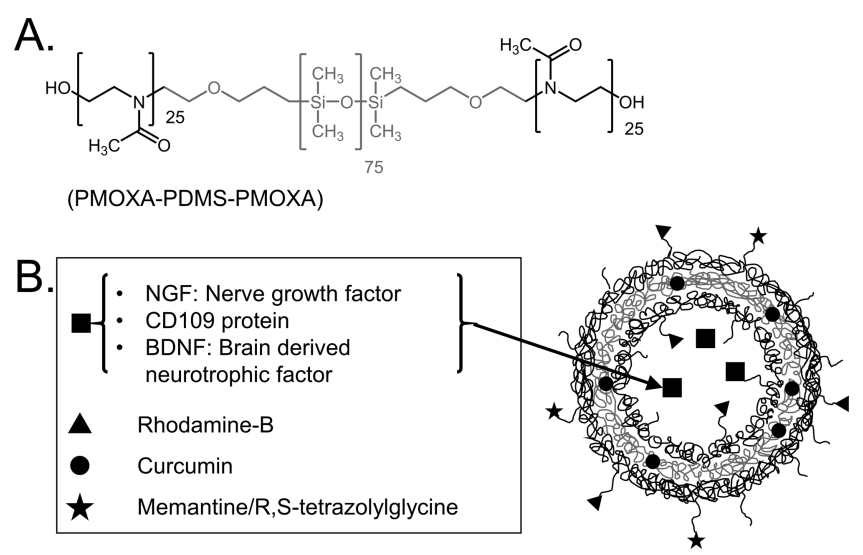

Figure 1. (A) Chemical structure of PMOXA-PDMS-PMOXA copolymer. (B) Pictorial representation of polymersomes incorporating proteins (NGF, CD109, or BDNF) or hydrophobic molecules (curcumin) and covalently labeled with rhodamine and the NMDAR antagonist or agonist [memantine or R,S-tetrazolylglycine (TZG)].

Curcumin and various proteins were incorporated into PMOXA-PDMS-PMOXA polymersomes (Figure 1B) using the standard film hydration method. The hydrophobic nature of curcumin allowed for its incorporation into the polymersome PDMS membrane with $82.3 \%$ encapsulation efficiency (EE, Table 1). The curcumin content of PMOXA-PDMSPMOXA polymersomes was $2.4 \%(\mathrm{w} / \mathrm{w})$, which corresponds to an equivalent curcumin concentration of $167.57 \mu \mathrm{M}$ for a polymersome concentration of $2.5 \mathrm{mg} / \mathrm{mL}$. Higher EE was observed with NGF over bovine serum albumin (BSA); however, because the mixing ration of protein/triblock was much higher for BSA compared to NGF, these numbers 
Table 1. Characteristics of PMOXA-PDMS-PMOXA-Based Polymersomes ${ }^{a}$

\begin{tabular}{|c|c|c|c|c|}
\hline complex & feed ratio $^{b}$ (wt drug/wt PMOXA-PDMS-PMOXA) & $R_{\mathrm{H}} \operatorname{DLS}(\mathrm{nm})$ & $\mathrm{LC}^{c}(\%)$ & $\mathrm{EE}^{d}(\%)$ \\
\hline empty polymersomes & $\mathrm{N} / \mathrm{A}$ & $66.1 \pm 1.0$ & $\mathrm{~N} / \mathrm{A}$ & $\mathrm{N} / \mathrm{A}$ \\
\hline polymersomes (BSA) & 0.322 & $68.4 \pm 1.3$ & 13.55 & 48.6 \\
\hline polymersomes (curcumin) & 0.03 & $62.3 \pm 0.6$ & 2.41 & 82.3 \\
\hline polymersomes (NGF) & 0.046 & $65.2 \pm 0.5$ & 4.4 & 100 \\
\hline \multirow[t]{2}{*}{ polymersomes (curcumin + NGF) } & 0.03 & $67.1 \pm 2.1$ & 2.32 & 80.5 \\
\hline & 0.019 & & 0.18 & 100 \\
\hline polymersomes (CD109) & 6.1 & $65.9 \pm 4.0$ & 20.72 & 4.3 \\
\hline polymersomes-memantine & 0.01 & $77.0 \pm 3.0$ & $\mathrm{~N} / \mathrm{A}$ & $\mathrm{N} / \mathrm{A}$ \\
\hline polymersomes-TZG & 0.01 & $75.5 \pm 3.8$ & $\mathrm{~N} / \mathrm{A}$ & $\mathrm{N} / \mathrm{A}$ \\
\hline
\end{tabular}

${ }^{a} \mathrm{DLS}=$ dynamic light scattering; $\mathrm{LC}=$ loading content; $\mathrm{EE}=$ encapsulation efficiency; $\mathrm{BSA}=$ bovine serum albumin; RhB = rhodamine; NGF = nerve growth factor; TZG $=R, S$-tetrazolylglycine. ${ }^{b}$ Ratio of initial drug to copolymer used to prepare the formulation. ${ }^{c} \mathrm{LC}=$ weight percent of the drug relative to copolymer in the final product. ${ }^{d} \mathrm{EE}=$ weight percent of drug content in the final formulation relative to amount added at the beginning of the process.
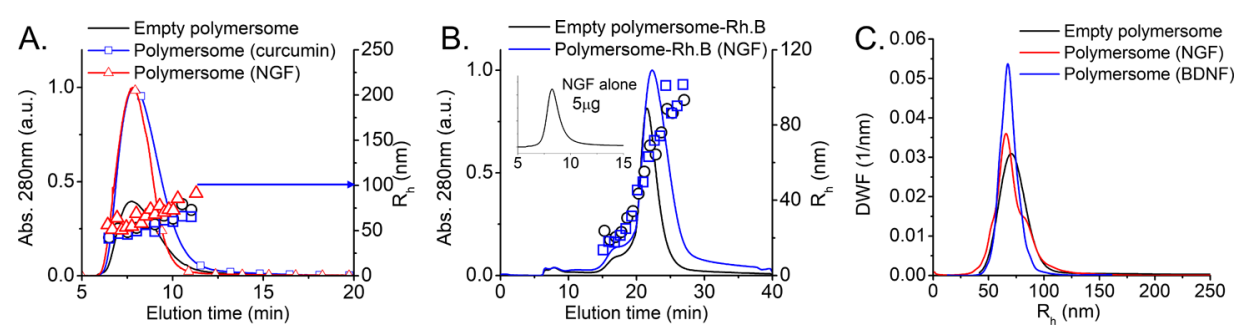

Figure 2. $\mathrm{AF}_{4}$ fractograms of PMOXA-PDMS-PMOXA polymersomes. (A) $\mathrm{AF}_{4} / \mathrm{UV} / \mathrm{DLS}$ fractograms monitored by the $\mathrm{UV}$ detector (left ordinate) and by DLS (right ordinate), using the $\mathrm{AF}_{4}$ method 1, showing the UV absorbance at $280 \mathrm{~nm}$ as a function of elution time for empty PMOXA-PDMS-PMOXA polymersomes (black curve), curcumin-loaded polymersomes (blue curve), and NGF-loaded polymersomes (red curve) in phosphate-buffered saline (PBS; $10 \mathrm{mM}, \mathrm{pH}$ 7.4); PMOXA-PDMS-PMOXA concentration: $0.5 \mathrm{~g} / \mathrm{L}$. The scattered symbols represent the hydrodynamic radii of the eluting polymersomes. (B) $\mathrm{AF}_{4}$ fractograms from $\mathrm{AF}_{4}$ method 2 of eluting rhodamine-labeled polymersomes with and without NGF. Both samples were injected at similar PMOXA-PDMS-PMOXA concentration (2.0 g/L). The elution of the polymersomes from the $\mathrm{AF}_{4}$ channel was also monitored by the fluorescence detector, the fluorescence elution profile matches well with the elution profile from the UV/vis detector (data not shown). (C) Size distribution of empty, NGF-loaded, and BDNF-loaded polymersomes plotted as the differential weight fraction as a function of the hydrodynamic radius $\left(R_{\mathrm{h}}\right)$.

cannot be compared. A remarkable EE was achieved with NGF (loading of $4.4 \mathrm{wt} \%$ ) with an initial mixing ratio of $4.6 \%$ (Table 1). A possible explanation for the high loading of NGF is its net positive charge at neutral $\mathrm{pH}(\mathrm{pI} \text { of } 9.3)^{56}$ compared to the net negative charge of BSA ( $\mathrm{pI}$ of 4.7$)^{57}$ and its smaller size $(27 \mathrm{kDa}$ vs $66.5 \mathrm{kDa})$. These results suggest that PMOXA-PDMS-PMOXA is particularly a suitable nanocarrier for trophic factors, such as NGF.

The size distribution of the polymersomes $(60<$ diameter < $400 \mathrm{~nm}$ ), determined by DLS, was relatively wide (Figure S4) with $R_{\mathrm{h}}$ values between $\sim 65$ and $75 \mathrm{~nm}$, depending on the sample (Table 1). Additional analysis of the polymersomes was performed by asymmetrical flow field-flow fractionation $\left(\mathrm{AF}_{4}\right)$ (Figures 2 and S11) to ascertain the incorporation of curcumin and NGF and to measure polymersome sizes using the onlineDLS detector. This method is known to be more precise than batch-mode DLS. ${ }^{58}$ The morphology of the polymersomes was assessed before and after loading of NGF by TEM (Figure S12). The electron micrographs show spherical structures with diameters ranging from 10 to $140 \mathrm{~nm}$. Size distribution after loading NGF was narrower.

The fractograms presented in Figure 2A, which monitor the absorption at $280 \mathrm{~nm}$ of the eluting species (left-hand ordinate), indicate that curcumin- and NGF-loaded polymersomes elute at elution times similar to the elution time of pristine polymersomes. The three eluting polymersomes have similar $R_{\mathrm{H}}$ values, as judged from the fractograms in Figure $2 \mathrm{~A}$ (right-hand ordinate). The size distributions of pristine polymersome alone and curcumin-loaded polymersomes are narrow, while polymersomes charged with NGF have a slightly broader size distribution and a larger $R_{\mathrm{H}}$ value. Rhodaminelabeled polymersomes loaded with NGF were fractionated by a modified elution protocol (method 2) designed to fractionate free NGF (elution time $\sim 9 \mathrm{~min}$ ) and NGF-loaded polymersomes (elution time $\approx 22 \mathrm{~min}$ ). As seen in Figure $2 \mathrm{~B}$, the NGF loading in the polymersomes was complete, with no detectable free NGF dissolved in the polymersome suspension. The rhodamine-labeled polymersomes incorporating NGF were larger than empty polymersomes by about $25 \mathrm{~nm}$ in $\mathrm{R}_{\mathrm{H}}$ value (Figure 2BC). We confirmed that NGF does not interact with the regenerated cellulose membrane used in the $\mathrm{AF}_{4}$ channel by analyzing NGF solutions of increasing concentration. The elution signal of NGF measured by the UV detector was proportional to the amount of NGF injected (Figure S5).

Release of curcumin by the polymersomes was assessed by a dialysis-based method. The results presented in Figure S6 indicate that the polymersomes sustain the release of curcumin over extended time. After a 48 h-incubation in a PBS saline solution ( $\mathrm{pH} 7.4$ ), about $70 \%$ of the initial curcumin is retained in the dialysis tube, hence within polymersomes. Dialysis of free curcumin in the same conditions leaves less than $4 \%$ curcumin in the dialysis bag. The NGF release from the polymersomes was measured using a dialysis bag method with a $50 \mathrm{kDa}$ cutoff membrane. In this case, we used a rhodamine-labeled NGF and measured the time-dependent Rho-NGF content of the polymersomes remaining in the 
dialysis bag by spectrofluorometry using the emission of rhodamine $\left(\lambda_{\text {ex }}=552 \mathrm{~nm}\right)$. Nearly $60 \%$ of the NGF remained encapsulated after a 24 h-incubation and 35\% NGF was still retained after $48 \mathrm{~h}$ (Figure S6C,D). The AF4 elution time of the polymersomes (Figure S7A) increases as a function of dialysis incubation time, which could be indicative of polymersome swelling for longer dialysis times. In addition, two new eluting species are observed, one at early elution times (left arrow, Figure S7A) and one at late elution times (right arrow for times 137 and $235 \mathrm{~h}$ ). The peak at early elution times corresponds to the triblock copolymers and free NGF (Figure S5), which provides evidence of the destabilization of the polymersomes. The large late eluting band (right arrow) is due to species larger than the polymersomes (ca. 700-800 nm, Figure S7B) could correspond to large aggregates which would assemble from the swollen polymersomes.

PMOXA-PDMS-PMOXA polymersomes loaded, or not, with curcumin and BSA were tested first in cell cultures of macrophages and human fibroblasts to assess the toxicity of polymer toward these cells. The cells selected are essential components of the skin, a target tissue innervated by DRG that we intend to use in the in vitro polymersomes evaluations in addition to 3D DRG cultures. The first task was to show that polymersomes are indeed not cytotoxic toward these cells, which were not evaluated in previous studies of PMOXAPDMS-PMOXA polymersomes.

A concentration-dependent evaluation of pristine PMOXAPDMS-PMOXA polymersomes confirmed that they do not impair the mitochondrial metabolic activity and do not reduce the number of viable cells (Figure 3). J774A.1 macrophage
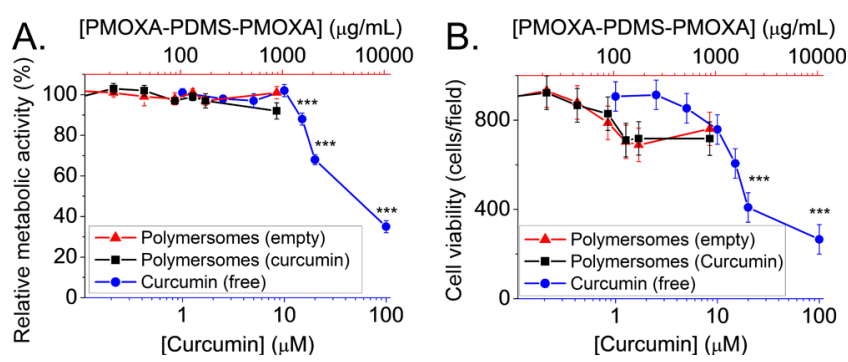

Figure 3. Polymersomes are well tolerated by macrophage cells. J774A.1 macrophage cells were incubated for $24 \mathrm{~h}$ with equimolar concentrations of polymersome nanoparticles (upward triangle), curcumin-loaded polymersomes (square), and curcumin alone (circle). (A) Mitochondrial metabolic activity was determined using the 3-(4,5-dimethylthiazol-2-yl)-2,5-diphenyl tetrazolium bromide (MTT) assay. The data are presented as the mean \pm standard error of the mean (SEM) obtained from at least three independent experiments. (B) Cell viability was determined by cell counting. Cell nuclei were labeled with Hoechst $33258(10 \mu \mathrm{M}, 10 \mathrm{~min})$ and 9 fields per sample were counted using a fluorescent microscope. The data are presented as the mean \pm SEM obtained from at least three independent experiments. Statistically significant differences from the untreated control were tested by Dunnett's test and are indicated by $* p<0.05, * * p<0.01, * * * p<0.001$.

cells were also incubated for $24 \mathrm{~h}$ with polymersomes without curcumin (triangle) or loaded with curcumin (square) and curcumin alone (circle) (Figure 3). There are only significant reductions in cell viability with relatively large free curcumin concentrations $(>10 \mu \mathrm{M})$, suggesting that the polymersomes could be suitable for the delivery of curcumin.
Considering that the site of injury is invaded rapidly by macrophages, it would be advantageous to exploit the phagocytic and macropinocytic properties of macrophages for delivery of drugs. This envisioned strategy promoted us to investigate the rate and extent of polymersomes internalization. Macrophages were treated with rhodamine-B ( $\mathrm{RhB})$-tagged polymersomes loaded with curcumin. Taking advantage of intrinsic fluorescence of curcumin, we detected the location of the polymersomes and their cargo (curcumin). Confocal fluorescence imaging revealed that polymersomes are internalized by J774A.1 macrophage cells within 5 min (Figure 4). Colocalization of $\mathrm{RhB}$ with curcumin was confirmed, proving that polymersomes are capable of delivering their cargo within cells.

Fibroblast migration is an indicator of wound healing, and models, such as the "wound in the dish" model, allow the evaluation of wound healing therapeutic agents. We used scratch assays to determine if the biological activity of compounds loaded into polymersomes is retained or, possibly, enhanced compared to their free form. The experimental conditions were set to measure the parameters of cell viability and migration required for a successful wound healing using both mouse and human fibroblasts (Figure 5). In this assay, an enhanced migration of fibroblasts toward the scratched surface is considered an indicator of promoted wound healing. We tested CD109-loaded polymersomes. The following control treatments were performed: (i) free fibroblast growth factor (FGF, $0.3 \mu \mathrm{M}$, a positive control for cell migration), (ii) free mitomycin C (MitC, $15 \mu \mathrm{M}$, an inhibitor of cell migration), and (iii) pristine polymersomes for $24 \mathrm{~h}$. Representative fluorescent micrographs are illustrated in Figure 5A with accompanying quantifications in Figure 5B. Treatment with FGF enhanced the fibroblast migration (1.55 fold), whereas treatment with $\mathrm{MitC}$ almost completely blocked fibroblast migration. Results from this assay show a significant increase in fibroblast migration, suggesting that FGF and CD109 might be beneficial in wound healing as noted also in earlier findings. ${ }^{48-51}$

Next, we investigated whether polymersome-loaded NGF can increase neurite outgrowth in peripheral DRG dissociated and $3 \mathrm{D}$ explant cultures. The restoration of nociceptive fields post skin denervation through the collateral sprouting by nearby undamaged nerves is dependent on endogenously produced NGF. ${ }^{39,60}$ Skin and muscle are the target tissues innervated by the nerves from the DRG. The experiments using DRG dissociated and explant 3D cultures described next were carried out to test if NGF retains its biological activity when incorporated into PMOXA-PDMS-PMOXA polymersomes (Figure 6A,B).

Neurite outgrowth of dissociated DRG neurons was enhanced significantly in the presence of NGF, with or without polymersomes as seen in Figure 6A,B. The extent of neurite outgrowth triggered by free NGF $(50 \mathrm{ng} / \mathrm{mL})$ and polymersome-incorporated NGF was comparable, although the NGF concentration within polymersomes was several-fold higher. In NGF release kinetics (Figure S6C,D), we observed that the amount of NGF released in the medium within $24 \mathrm{~h}$ corresponds to $40 \%$ of the initial content. Nerves in the target tissues (skin and muscle) are NGF-responsive in the wound healing processes. Further studies are necessary to assess if and how polymersome-incorporated trophic factors combined with small molecules are advantageous in re-establishing normal collateral sprouting and enhancing the rate of wound closure in animal models. We tested also NGF-containing polymersomes 


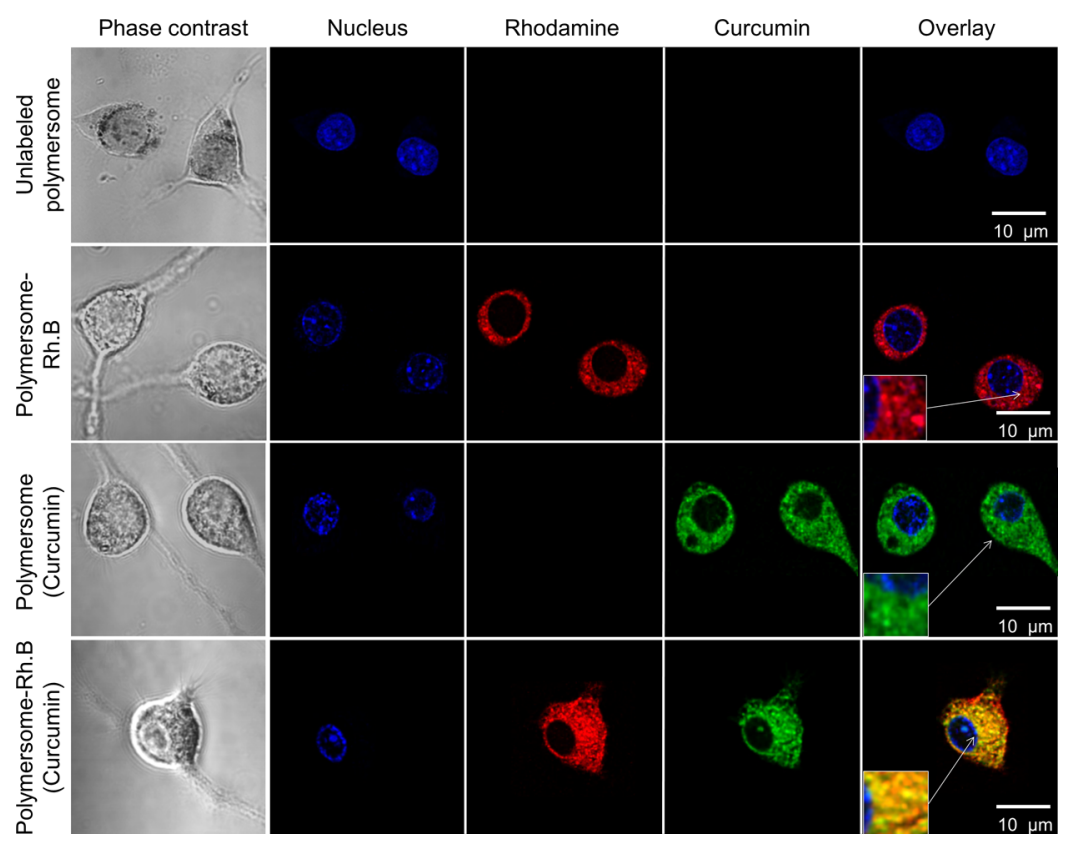

Figure 4. Polymersomes are rapidly internalized by macrophage cells. J774A.1 macrophage cells were imaged using a live cell confocal microscope. Cell nuclei were labeled with Hoechst 33258 or DRAQ5 (pseudo-color blue) and treated with polymersomes labeled with RhB (polymersomes$\mathrm{RhB})(5 \mu \mathrm{M}$, based on polymer concentration). Images were acquired at $t=5 \mathrm{~min}$. Scale bars $=10 \mu \mathrm{m}$. Representative fluorescent micrographs from at least three independent experiments are shown.
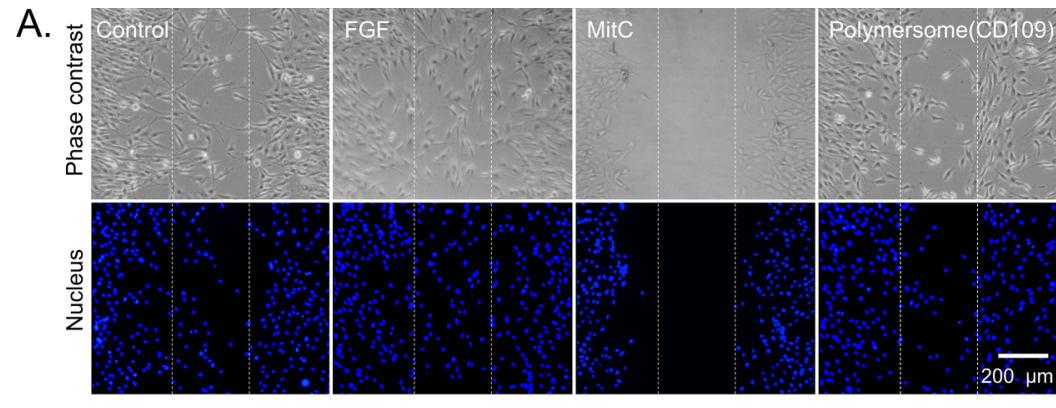

B.

- NIH 3T3 口Human Fibroblasts

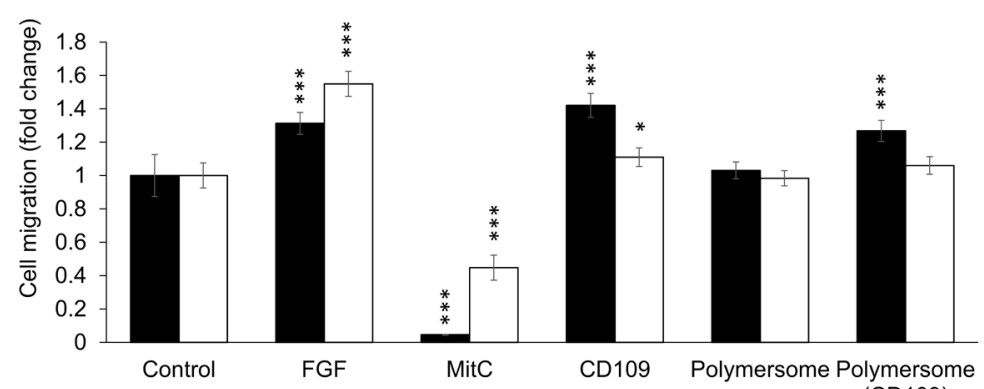

(CD109)

Figure 5. (A) Fibroblast cell migration was measured using an in vitro scratch assay. Monolayer fibroblast cells (human and murine cells) were scratched with a pipette tip prior to treatment. Control treatments were (i) FGF (0.291 $\mu \mathrm{M})$, (ii) MitC (15 $\mu \mathrm{M})$, and (iii) CD109 (10 $\mu \mathrm{M})$ for 24 $\mathrm{h}$. Representative fluorescent micrographs showing fibroblast cell migration after $24 \mathrm{~h}$ are shown in (A). The scratch is denoted by the dashed white vertical lines. Scale bar $=200 \mu \mathrm{m}$. (B) Number of migrating cells to the vicinity of the scratch area expressed as the fold change in cell migration with respect to the control (set to 1). The data are presented as the mean \pm SEM obtained from at least three independent experiments performed in triplicates. Statistically significant differences from the untreated control were tested by Dunnett's test and are indicated by $* p<0.05, * * p<0.01$, $* * * p<0.001$.

in a $3 \mathrm{D}$ model of the peripheral nervous system (DRG explants, Figure 6C,D) and noted that these polymersomes significantly promote the neurite outgrowth. Three-dimensional models both for peripheral and central nervous system have a number of advantages over dissociated cultures including retained connections, the ability to monitor long term time-dependent changes from progenitor to fully differentiated cells, and more reliable testing of therapeutic interventions. ${ }^{61-63}$

Both peripheral nerves and central nervous system tissues respond to BDNF. BDNF has been established as a crucial trophic factor in brain development ${ }^{64}$ and neurological 

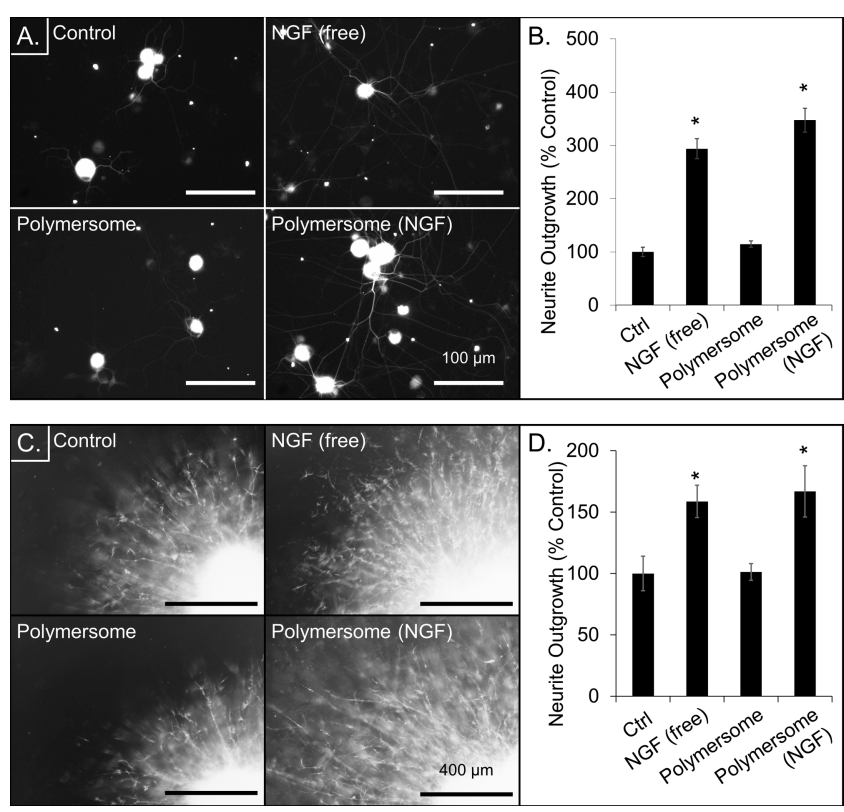

Figure 6. (A) Dissociated DRG cultures treated with NGF-loaded polymersomes increase neurite outgrowth. Phase contrast micrographs. Scale bar $=100 \mu \mathrm{m}$. (B) Quantification of the neurite outgrowth. Note the significant increase of neurite outgrowth with NGF treatment. (C) Bright-field photomicrographs of DRG explants after 4 days in culture. To enhance the contrast of neural cells against the background, we used MTT $(500 \mu \mathrm{g} / \mathrm{mL}, 3 \mathrm{~h})$ and imaged with a light microscope at $10 \times$ (Leica DMI6000B). Images were analyzed using ImageJ. Scale bar $=400 \mu \mathrm{m}$. (D) Quantification of the neurite area expressed as a percentage of control (PBS) $(n=8)$. The total neurite area is normalized as shown in Figure S9. Error bars represent SEM. $* p<0.05$.

disorders. ${ }^{65-67}$ Despite the positive neutrophic effects of BDNF, clinical use of BDNF has been hampered by its instability and rapid clearance; BDNF has a circulating half-life of $\sim 10$ min. ${ }^{68}$ We explored polymersome delivery of neurotrophic protein BDNF in the central nervous system using mouse hippocampal 3D organotypic slice cultures. BDNF is a crucial regulator of memory formation in the hippocampus. $^{69}$ It is known to increase dendritic spine density $^{70,71}$ and to facilitate LTP. ${ }^{72}$ The hippocampus, an area associated with memory formation, is especially sensitive to traumatic brain injury (TBI). Even mild TBI, which does not produce systematic vascular injury or neuronal loss, causes dendritic and synaptic degeneration. ${ }^{73}$ Repeated mild TBI leads to loss of long-term potentiation. ${ }^{74}$

We observed that polymersome-loaded BDNF has an activity comparable to that of free BDNF on modulating dendritic spine density in organotypic hippocampal cultures (Figure 7A,B). While treatment with pristine polymersomes (concentration-matched control, $211 \mu \mathrm{g} / \mathrm{mL}, 72 \mathrm{~h}$ ) did not significantly affect either the subtype or the total density of dendritic spine density in serum-free media, application of free BDNF (100 ng/mL, $72 \mathrm{~h})$ or polymersome-incorporated BDNF (100 ng/mL BDNF, $211 \mu \mathrm{g} / \mathrm{mL}$ polymersomes, $72 \mathrm{~h}$ ) significantly increased the total dendritic spine density compared to both controls: hippocampi not treated with polymersomes or treated with drug-free polymersomes in serum-free media.

Spine morphology and density contribute to the synaptic plasticity and functions. Several NMDA receptor agonists and antagonists have been evaluated for modulating synaptic functions in different models. ${ }^{75,76}$ Compounds investigated include TZG and memantine, potent agonist and antagonist, respectively. ${ }^{77,78}$ Memantine-coated gold nanoparticles have been shown to target exclusively extrasynaptic NMDAR as the large size prevents their entry in the synaptic cleft. This spatial segregation allows blocking of extrasynaptic NMDAR without affecting synaptic NMDAR. Savchenko et al. have shown that the gold nanoparticles exhibit neuroprotective effect by reducing glutamatergic cytotoxicity. ${ }^{79} \mathrm{We}$ functionalized the surface of polymersomes with TZG or memantine and imaged them in mixed cortical cultures. Preliminary results (Figure S13) indicate memantine, and TZG-functionalized rhodaminelabeled polymersomes are predominantly found in neurons, whereas rhodamine-labeled polymersomes that do not present memantine or TZG are present in both glial cells and neurons. Thus, follow-up studies should evaluate electrophysiological parameters in models of central nervous system pathologies.

In summary, the study presented here demonstrates that PMOXA-PDMS-PMOXA self-assembles to form highly colloidally stable polymersomes that are nontoxic to murine macrophages, human fibroblast cells, and 3D models (DRG explants and hippocampal organotypic slice cultures). It suggests that surface-modified PMOXA-PDMS-PMOXA polymersomes could be useful nanocarriers for various trophic factors, such as neurotrophin-3, insulin-like growth factor, and in combination with small biologically active agents or synaptic modulators. Collectively, PMOXA-PDMS-PMOXA polymersomes merit further investigations in disease models in
A.

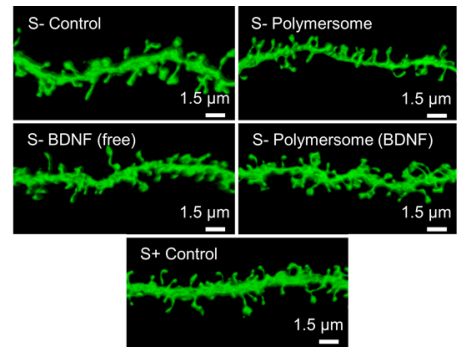

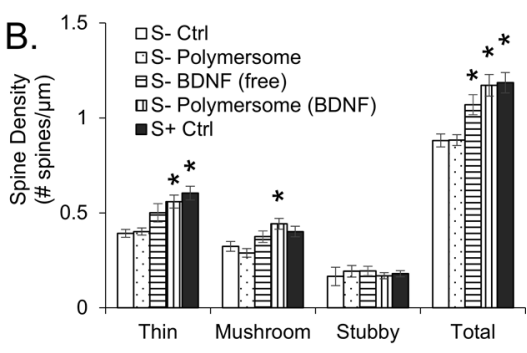

Figure 7. Polymersome-incorporated BDNF increases postsynaptic dendritic spine density of pyramidal neurons in organotypic hippocampal slice cultures. Cultures were treated with BDNF (100 ng/mL), polymersome-loaded BDNF (100 ng/mL BDNF; $211 \mu \mathrm{g} / \mathrm{mL}$ polymersome), or empty polymersomes $(211 \mu \mathrm{g} / \mathrm{mL})$ for $72 \mathrm{~h}$ in serum-free media $(\mathrm{S}-)$. Serum-containing media $(\mathrm{S}+)$ acted as a positive control. (A) Representative photomicrographs of dendritic spines. Scale bar $=1.5 \mu \mathrm{m}$. (B) Quantification of spine density and subtype exposed to above conditions. $n \geq 12$ spine segments from at least four independent samples. Statistical significance was assessed by one-way ANOVA followed by Dunnett's test. * $p<$ 0.05 compared to $S-$ Ctrl. 
vivo to evaluate if they are superior to the unincorporated agents at the peripheral and central target tissues. Polymersomes-containing proteins and small lipophilic molecules provide new avenues for multidrug therapies to be considered for interventions in neurological disorders.

\section{EXPERIMENTAL SECTION}

Chemicals. BSA (98\%, electrophoresis), curcumin (from Curcuma longa (Turmeric), FGF, laminin, PKH67, MitC, MTT, RhB-isothiocyanate, Hank's balanced salt solution (HBSS), sodium chloride $(\mathrm{NaCl}), \alpha, \alpha, \alpha$-trifluorotoluene, poly(dimethylsiloxane), 2-methyl-2-oxazoline, 1,2-dichloroethane, trifluoroacetic anhydride, deuterated chloroform $\left(\mathrm{CDCl}_{3}\right)$, dimethyl-sulfoxide (DMSO), triethylamine (99\%), 4-(dimethylamino)pyridine (DMAP, 99\%), succinic anhydride (99\%), N-hydroxysuccinimide (NHS, 98\%), N, $N_{0}$-dicyclohexylcarbodiimide (DCC, 99\%), and anhydrous dichloromethane (99.8\%, containing 50-150 ppm amylene as stabilizer) were purchased from Sigma-Aldrich (St. Louis, MO, USA). Regenerated cellulose dialysis membranes [molecular weight cutoff (MWCO): $3.5 \mathrm{kDa}$ ] were obtained from Spectrum Labs (Rancho Dominguez, CA, USA). NGF 2.5S was purified from male mouse salivary glands. ${ }^{59}$ Recombinant human CD109 protein was a gift of Dr. Anie Philip. Anhydrous ethanol was purchased from GreenField Specialty Alcohols Inc. (Toronto, ON, Canada). Sephacryl S-300 HR ( $\left.M_{\mathrm{w}}: 10-1500 \mathrm{kDa}\right)$ was purchased from GE Healthcare Bio-Sciences (Pittsburg, PA, USA). PBS, Dulbecco's modified Eagle's medium (DMEM), bovine calf serum, and penicillin-streptomycin were purchased from Gibco (Thermo Fisher Scientific, Waltham, MA, USA). Rat tail collagen and RPMI-1640 were purchased from Invitrogen (Thermo Fisher Scientific, Waltham, MA, USA). Paraformaldehyde was purchased from Fisher Scientific (Waltham, MA, USA). Hoechst 33258 and AlexaFluor 488 goat anti-mouse were purchased from Molecular Probes (Eugene, OR, USA). Trypsin was purchased from Worthington Biochemical Corp. (Lakewood, NJ, USA). $\beta$-Tubulin III was purchased from EMD Millipore (Billerica, MA, USA).

Triblock Copolymer Synthesis. $\mathrm{PMOXA}_{25}-\mathrm{PDMS}_{75}-$ $\mathrm{PMOXA}_{25}$ was prepared following a known procedure (Figure $\mathrm{S} 1){ }^{26}$ Its synthesis is given in Supporting Information, together with its structure and characterization by NMR spectroscopy and GPC. The PDMS block has 75 units and the PMOXA blocks have each 25 monomer units.

Polymersome Preparation and Loading. Polymersomes were formed by the film hydration method. ${ }^{26,80}$ $\mathrm{PMOXA}_{25}-b-\mathrm{PDMS}_{75}-b$ - $\mathrm{PMOXA}_{25}(10 \mathrm{mg})$ was placed in a round-bottom flask and dissolved with $2 \mathrm{~mL}$ of ethanol for $1 \mathrm{~h}$. The ethanol evaporated under reduced pressure at a temperature of $40{ }^{\circ} \mathrm{C}$, and the resulting thin polymer film was dried for $4 \mathrm{~h}$ under vacuum at room temperature. Subsequently, the film was rehydrated using a solution of PBS (10 mM, pH 7.4, $137 \mathrm{mM} \mathrm{NaCl}, 4 \mathrm{~mL}$, final PMOXAPDMS-PMOXA concentration of $2.5 \mathrm{mg} / \mathrm{mL}$ ). The flask was placed on a rotary agitator at room temperature for agitation overnight and then stirred magnetically for $4 \mathrm{~h}$ with a small Teflon stirring bar. The polymersome suspension was extruded (11 times) through polycarbonate membranes $(0.4 \mu \mathrm{m}$ pore size followed by $0.1 \mu \mathrm{m}$ pore size, Avestin, Ottawa, ON, Canada) to adjust the polymersomes size and sharpen the size distribution.

Curcumin was loaded during the film formation by adding $0.3 \mathrm{mg}$ of curcumin to the polymersome solution and sonicated for $30 \mathrm{~s}$ prior to ethanol evaporation. For protein loading, NGF 2.5S (26 kDa), BDNF (27 kDa), CD109 (180 $\mathrm{kDa})$, or BSA $(66.5 \mathrm{kDa})$ were dissolved in the PBS aqueous solution used to rehydrate the polymer film. Excess free protein was removed by filtration through centrifugal filter units with an MWCO of $100 \mathrm{kDa}$ (Amicon, EMD Millipore, Billerica, MA, USA). Free CD109 was separated from polymersome-encapsulated CD109 using Sephadex G-200 gel filtration columns (Sigma-Aldrich, St. Louis, MO, USA).

Curcumin and Protein Loading Content Determination. For curcumin content determination, an aliquot of the solution after rehydration was kept and diluted 200 times using a solution of Tween 80 (1\%) in PBS. An aliquot of identical volume of the polymersomes suspension after extrusion and removal of excess free curcumin was also diluted 200 times in a Tween 80 solution. Both samples were analyzed by fluorescence spectroscopy $\left(\lambda_{\mathrm{ex}}=431 \mathrm{~nm}, \lambda_{\mathrm{em}}=534 \mathrm{~nm}\right)$. The EE was found by summing the areas under the emission bands for the two aliquots, and the concentration of encapsulated curcumin was calculated by multiplying the EE and the initial concentration of curcumin used. The equations for $\mathrm{EE}$ and loading content calculations are found below

$$
\begin{aligned}
& \text { EE (weight \%) } \\
& =\frac{\text { weight of drug or protein in the polymersomes }}{\text { weight of the drug or protein used initially }} \\
& \times 100 \% \\
& \text { Loading content (weight \%) } \\
& =\frac{\text { weight of drug or protein in the polymersomes }}{\text { total weight of the polymersomes tested }} \\
& \times 100 \%
\end{aligned}
$$

The amount of protein in the polymersomes was determined by UV absorbance spectroscopy. The absorption spectrum of the sample after preparation was compared to that of polymersomes prepared under identical conditions but without proteins. The protein-loaded polymersomes were purified by centrifugal filtration through $100 \mathrm{kDa}$ membranes (EMD Millipore, Billerica, MA, USA) or G-200 Sephadex columns for CD109 separation to remove free protein. Fresh PBS was added to the recovered polymersomes that were subjected to three additional filtrations. A UV-absorption spectrum of the retentate, diluted to its initial volume with fresh PBS, was measured. The EE was determined as the ratio of the absorbance of the suspensions after and before filtration $(\lambda=$ $280 \mathrm{~nm})$.

RhB Labeling of PMOXA-PDMS-PMOXA. To detect the formation of polymersomes and their internalization in cells (in vitro), the copolymer PMOXA-PDMS-PMOXA was labeled by conjugating $\mathrm{RhB}$ isothiocyanate to the $-\mathrm{OH}$ end groups. $\mathrm{RhB}$ isothiocyanate in dichloromethane $(0.5 \mu \mathrm{mol})$ was added to PMOXA-PDMS-PMOXA (0.01 mmol) dissolved in dichloromethane $(1 \mathrm{~mL})$ and left to react for 10 $h$ at RT. Excess RhB was removed by dialysis first in ethanol and then again in deionized water (MWCO $5 \mathrm{kDa}$ ) for $48 \mathrm{~h}$ followed by at least three exchanges with water. The RhBtagged polymer was isolated by lyophilization.

RhB Labeling of BSA and NGF. BSA (10 mg), or NGF $(0.5 \mathrm{mg})$, was dissolved in aqueous sodium bicarbonate buffer (0.1 M, $1 \mathrm{~mL}, \mathrm{pH}$ 8.5). A solution $(50 \mu \mathrm{L})$ of $\mathrm{RhB}$ 
isothiocyanate in dimethylformamide $(10 \mathrm{mg} / \mathrm{mL})$, briefly sonicated and stirred, was added to a stirred BSA solution (or $6.3 \mu \mathrm{L}$ for NGF solution) for $1 \mathrm{~h}$ at room temperature. RhBlabeled proteins were purified from free dye by two consecutive elutions through Sephadex G25 columns.

Labeling of PMOXA-PDMS-PMOXA with Drugs. Dicarboxyl acid-modified poly(2-methyl-2-oxazoline)-blockpoly(dimethylsiloxane)-block-poly(2-methyl-2-oxazoline) triblock copolymers (HOOC-PMOXA $25-b$-PDMS ${ }_{75}-b$ $\left.\mathrm{PMOXA}_{25}-\mathrm{COOH}\right)$ were synthesized as follows: succinic anhydride $(39 \mathrm{mg}, 0.39 \mathrm{mmol})$, triethanolamine $(50 \mu \mathrm{L}, 0.36$ mmol), and DMAP (6.9 mg, $0.06 \mathrm{mmol}$ ) were added to a solution of $\mathrm{HO}-\mathrm{PMOXA}_{25}-b$-PDMS $\mathrm{PD}_{75}-b-\mathrm{PMOXA}_{25}-\mathrm{OH}$ (500 $\mathrm{mg}, 0.07 \mathrm{mmol}$ ) in anhydrous dichloromethane at $0{ }^{\circ} \mathrm{C}$ under argon and reacted for $24 \mathrm{~h}$. The reaction mixture was dialyzed against dichloromethane for 2 days while changing the dichloromethane four times. NHS-activated ester-modified

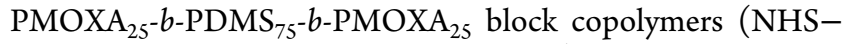

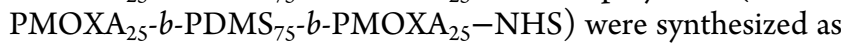
follows: NHS (30 mg, $0.26 \mathrm{mmol}$ ) and DCC (35 mg, 0.17 mmol) were added to an anhydrous dichloromethane solution of $\mathrm{HOOC}-\mathrm{PMOXA}_{25}-b$ - $\mathrm{PDMS}_{75}-b-\mathrm{PMOXA}_{25}-\mathrm{COOH}$ (300 $\mathrm{mg}, 0.04 \mathrm{mmol}$ ) at room temperature under argon. The mixture was maintained in this condition for $24 \mathrm{~h}$. Finally, it was dialyzed against dichloromethane for 2 days while changing dichloromethane four times, followed by dialysis against methanol to remove dichloromethane. The NHS-

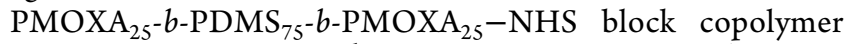
was characterized by ${ }^{1} \mathrm{H}$ NMR spectroscopy (solvent: $\mathrm{CDCl}_{3}$; Figure S10).

Polymersomes were prepared with 5\% rhodamine-labeled PMOXA-PDMS-PMOXA and 95\% unlabeled PMOXAPDMS-PMOXA or 5\% rhodamine-labeled PMOXAPDMS-PMOXA, 5\% NHS-terminated PMOXA-PDMSPMOXA, and 90\% unlabeled PMOXA-PDMS-PMOXA in the case of drug-attached polymersomes. The triblocks were mixed in methanol at the molar ratios described above. Methanol was evaporated using a rotary evaporator. The film was rehydrated at a concentration of $2.5 \mathrm{mg} / \mathrm{mL}$ in HEPES buffer (10 mM, pH 7.4) for several hours. The solution was sonicated for $30 \mathrm{~s}$ before being extruded through $0.4 \mu \mathrm{m}$ polycarbonate filters (Avestin) 11 times, followed by $0.1 \mu \mathrm{m}$ polycarbonate filters 11 times. A 10 -fold excess, with respect to the calculated amount of -NHS groups on the surface of the polymersome, of an amine-containing drug over was added to the extruded polymersomes. The excess unreacted drug was removed by ultracentrifugal filtration through $3 \mathrm{kDa} \mathrm{MWCO}$ filters (Pall Centrifugal Nanosep $3 \mathrm{kDa}$ ) spinning the tubes for $20 \mathrm{~min}$ at $7000 \mathrm{~g}$. The retentate was rinsed with HEPES buffer, and the centrifugation was repeated three times. The last retentate was diluted to obtain a polymersomes $(2.5 \mathrm{mg} / \mathrm{mL})$ solution. The polymersome size was determined by $\mathrm{AF}_{4} / \mathrm{UV} /$ DLS (see below).

Curcumin and NGF Release from Polymersomes. Curcumin release from polymersomes was measured using the dialysis bag method in a solution of PBS and Tween 80 (1\%, $\mathrm{v} / \mathrm{v})$. Tween 80 was added to solubilize curcumin, which has a low solubility in PBS. A suspension of curcumin-loaded polymersomes in PBS-Tween $80\left(2 \mathrm{~mL}, C_{\text {Cur }}=0.07 \mathrm{mg} / \mathrm{mL}\right)$ was introduced in a dialysis tube $(\mathrm{MWCO}=20 \mathrm{kDa}$, Slide-ALyzer MINI Dialysis, $2 \mathrm{~mL}$ ) and dialyzed against PBS-T (44 $\mathrm{mL}$ ) at $37{ }^{\circ} \mathrm{C}$. At predetermined time intervals, the entire release medium was replaced by fresh medium to maintain perfect sink conditions for curcumin. A solution of curcumin (0.1 mg/mL in PEG400-water-dimethylacetamide (45:40:15 $\mathrm{v} / \mathrm{v} / \mathrm{v}$ ) was used as a control. Curcumin concentration in the release samples was measured using spectrofluorometry. The concentration of curcumin in the dialysis compartment was determined as well by taking aliquots $(50 \mu \mathrm{L})$ and diluting them 100 -fold in ethanol before spectra analysis.

A solution of PMOXA-PDMS-PMOXA polymersomes loaded with RhB-labeled NGF $(5 \mathrm{~mL}$, polymersome concentration: $0.7 \mathrm{mg} / \mathrm{mL}$ ) was placed in a dialysis tube (MWCO: $50 \mathrm{kDa}$ ) and dialyzed against PBS $(1 \mathrm{~L})$ at $37^{\circ} \mathrm{C}$ for several days. Aliquots of the solution in the dialysis bag were taken over time and analyzed by UV absorbance, fluorescence, and $\mathrm{AF}_{4}$. The PBS solution was replaced with fresh PBS at these times.

Asymmetrical Flow Field-Flow Fractionation. Information about the instrument used and the two methods developed for the analysis of the polymersomes can be found in the Supporting Information section.

Transmission Electron Microscopy. Data were collected on an FEI Tecnai 12 BioTwin $120 \mathrm{kV}$ TEM. Images were taken with an AMT XR80C CCD Camera System. Carboncoated grids were first treated in a glow-discharge apparatus set at negative $25 \mathrm{~mA}$ for $30 \mathrm{~s}$. Rapidly after, a drop of the polymersome sample (stock concentration at $2.5 \mathrm{mg} / \mathrm{mL}, 5$ $\mu \mathrm{L}$ ) was deposited on the grid and left for $1 \mathrm{~min}$. A Whatman filter paper was used to wick away excess sample by slowly bringing it into contact with the side of the grid. A uranyl acetate solution (2\%) was used as a negative staining agent, a 5 $\mu \mathrm{L}$ drop was deposited and left for 1 min before being wicked away with a clean Whatman filter paper. The grids were placed on a Whatman filter paper and left to dry in a Petri dish at room temperature until imaging ( $>15 \mathrm{~min}$ ).

Macrophage Cultures and Live Cell Imaging. Mouse macrophage (J774A.1) cells (ATCC, TIB-67) were cultured in DMEM containing $10 \%$ fetal bovine serum and $1 \%$ penicillinstreptomycin. Cells were used between 5 and 25 passages.

In preparation for live cell imaging, macrophages were seeded at a density of 20000 cells/coverslip onto rat tail collagen-coated cover slips (Fisher Scientific). Following cell treatment, plasma membranes were labeled with $2 \mu \mathrm{M}$ PKH67 for $15 \mathrm{~min}$ and subsequently washed with PBS containing $1 \%$ BSA for $5 \mathrm{~min}$. Prior to imaging, cells were washed with PBS containing 1\% BSA for 5 min. Fluorescence micrographs were acquired with a Zeiss LSM 710 confocal microscope with Zeiss Zen imaging software at $63 \times$ magnification.

MTT Cell Viability Assay. We assessed mitochondrial activity, an indirect measure of cell viability using the colorimetric MTT assay. Macrophage cells were seeded at 100000 cells/well in 24-well plates (Sarstedt, Nümbrecht, Germany). Following treatment, cell media was removed and replaced with serum-free media containing MTT $(0.5 \mathrm{mg} /$ $\mathrm{mL}$ ), and cells were then incubated for $1 \mathrm{~h}$ at $37^{\circ} \mathrm{C}$. Following the incubation, media were removed, cells were lysed, and formazan was dissolved with DMSO. The dye absorbance was measured at $595 \mathrm{~nm}$ using a Benchmark microplate reader (Bio-Rad Life Science Research, Hercules, CA, USA). All measurement points were done in triplicates in three or more independent experiments.

Human and Mouse Fibroblast Cultures and Scratch Assay. Human fibroblast cells and mouse 3T3 fibroblast cells were seeded in DMEM containing $10 \%$ of fetal bovine serum 
and $1 \%$ penicillin-streptomycin. Cells were used between 5 and 25 passages.

Both mouse 3T3 fibroblasts cells and human fibroblasts were seeded at 100000 cells per well in 24 well plates, grown to confluency and scratched with a $100 \mu \mathrm{L}$ pipette and washed with DPBS to remove detached cells. Fresh serum-containing media was added, and cells were treated with (i) FGF (0.3 $\mu \mathrm{M})$; (ii) MitC (15 $\mu \mathrm{M})$; and (iii) curcumin $(24.4 \mu \mathrm{M})$ for 24 h. Cells were then washed once with PBS and fixed with paraformaldehyde (4\%) for $15 \mathrm{~min}$ at room temperature. Cell nuclei were labeled with Hoechst $33258(10 \mu \mathrm{M}, 10 \mathrm{~min})$, and fluorescent images of the scratch area were acquired. Fluorescent images of cells were acquired at $20 \times$ with a Leica DFC350FX monochrome digital camera connected to a Leica DMI4000B inverted fluorescence microscope. Cell migration was quantified using ImageJ and expressed as fold change in the number of cells in the scratch area over the control.

DRG Cultures Preparation and Imaging. Dissociated DRG Preparation, Live Imaging, Neurite Outgrowth Assay. L1-L5 DRG neurons were cultured from P5-P7 C57BL/6J mice. The ganglia were dissociated in $0.1 \%$ trypsin in $1 \times$ HBSS for $45 \mathrm{~min}$ at $37{ }^{\circ} \mathrm{C}$ followed by gentle mechanical trituration using a fire-polished pipette. Dissociated cells were grown on laminin-coated 96-well plates (Corning Inc., Corning, NY, USA) and in growth media consisting of L-15 (Wisent Bio Products, St. Bruno, QC, Canada) supplemented with vitamins, cofactors, and penicillin-streptomycin.

In preparation for live cell imaging, dissociated DRG were cultured in $50 \mathrm{ng} / \mathrm{mL}$ free NGF for $24 \mathrm{~h}$. After $24 \mathrm{~h}$, cells were incubated for $24 \mathrm{~h}$ with a $50000 \mathrm{ng} / \mathrm{mL}$ suspension of RhBlabeled polymersomes loaded with NGF or a polymersomeNGF suspension. Fifteen minutes before the end of treatment, the cell nucleus was stained with Hoechst 33342 at $10 \mu \mathrm{M}$ for $15 \mathrm{~min}$. Cells were washed with PBS and imaged live using fluorescence microscopy (a Leica DFC345FX monochrome digital camera connected to a Leica DMI6000B inverted fluorescence microscope).

To quantify neurite outgrowth, dissociated DRG were treated with vehicle (PBS, control), empty polymersomes, free NGF (50 ng/mL), or polymersome-loaded NGF (50 ng/ $\mathrm{mL} \mathrm{NGF)} \mathrm{for} 24 \mathrm{~h}$. After $24 \mathrm{~h}$ in culture, cells were fixed with $4 \%$ paraformaldehyde for $20 \mathrm{~min}$ at room temperature and permeabilized with $0.3 \%$ Triton $\mathrm{X}$ for $5 \mathrm{~min}$. Neurons were immunocytochemically labeled with $\beta$-tubulin III (1:500, MAB1637) overnight at $4{ }^{\circ} \mathrm{C}$ and AlexaFluor 488 goat antimouse (1:500, \#A11005) for $1 \mathrm{~h}$ at room temperature. Images were taken with a fluorescence microscope (Leica DMI6000B). Neurite length was measured manually using the ImageJ extension NeuronJ. ${ }^{81}$ The total neurite length in pixels was normalized to the number of cell bodies and expressed as percentage control.

Explant DRG Preparation and Explant Imaging. L3-L5 DRG were isolated from P5-7 mice as described above. Explants were embedded in Matrigel (BD Biosciences, Franklin Lakes, NJ, USA) and surrounded with RPMI-1640 supplemented with penicillin-streptomycin. Following embedding, explants were treated with vehicle (PBS, control), empty polymersomes, free NGF $(50 \mathrm{ng} / \mathrm{mL})$, or polymersome-loaded NGF (50 ng/mL NGF).

After 4 days in culture, a MTT solution $(500 \mu \mathrm{g} / \mathrm{mL})$ was added to the cultures and incubated for $3 \mathrm{~h}$. Bright-field pictures for the DRG were taken at $10 \times$ (Leica DMI6000B) and analyzed using ImageJ. Images were inverted, and neurite outgrowth was quantified as the total area of bright areas (MTT-labeled regions), excluding the explant body, normalized against the length of the explant body in the image, and expressed as percentage control.

Primary Dissociated Hippocampal Neural Cultures Preparation and Live Imaging. Primary dissociated hippocampal neural cultures were prepared from $\mathrm{P} 0-\mathrm{P} 2$ postnatal C57/BL6 mice. Hippocampi were dissected and placed in icecold $1 \times$ HBSS. The tissues were softened in $0.25 \%$ trypsin [2.5\% Trypsin (Thermo Fisher) diluted 10-fold into $1 \times$ HBSS] for $20 \mathrm{~min}$ at $37^{\circ} \mathrm{C}$ and $0.1 \%$ DNAse I (Sigma DN25) for $5 \mathrm{~min}$ at $37^{\circ} \mathrm{C}$. Tissues were washed twice in plating media (Neurobasal medium (Thermo Fisher) $+2 \mathrm{mM}$ L-glutamine (Thermo Fisher $)+10 \%$ fetal bovine serum $+1 \%$ penicillinstreptomycin) and mechanically dissociated by triturating with a fire-polished pipette. Cells were plated onto PDL (Sigma)coated chamber slides in plating media for $24 \mathrm{~h}$ and switched to serum-free maintenance media (Neurobasal medium +2 $\mathrm{mM}$ L-glutamine $+2 \% \mathrm{~B} 27+1 \%$ penicillin-streptomycin). Neural cultures were feed every 3 days by changing $50 \%$ of the maintenance media and were used after 12 days in culture. Cells were treated as described in the corresponding figure and live-imaged using fluorescence microscopy (Leica DMI6000B). All animal uses followed the McGill University animal use guidelines and were approved by the McGill Animal Care Committee.

Organotypic Hippocampal Culture Preparation, Imaging, and Spine Classification. Preparation of organotypic hippocampal cultures were extensively described in Gähwiler et al. ${ }^{82}$ Cultures were prepared from P6- 8 transgenic mice that express Thy-1 driven eGFP in a subpopulation of CA1 neurons. Hippocampi were transversely sliced $400 \mu \mathrm{m}$ thick and mounted onto glass coverslips using chicken plasma clot (Cocalcol Biologicals; Reamstown, PA, USA). The culture medium consisted of $25 \%$ heat-inactivated horse serum, $25 \%$ HBSS, and 50\% Basal Medium Eagle. Serum-free medium consisted of $67 \%$ Basal Medium Eagle and 33\% HBSS supplemented with $12.5 \mathrm{mM}$ glucose and $1.25 \mathrm{mM} \mathrm{L}$ glutamine. Cultures were incubated for 3 weeks in a roller drum incubator before experimentation. Cultures were treated with vehicle (PBS, control), empty polymersomes, free BDNF $(100 \mathrm{ng} / \mathrm{mL})$, or BDNF-loaded polymersomes. After treatment, cultures were fixed in $4 \%$ PFA overnight at $4{ }^{\circ} \mathrm{C}$, washed with $\mathrm{PBS}$, and mounted onto microscope slides. Image stacks of CA1 pyramidal neurons expressing eGFP were taken at $Z=$ $0.2 \mu \mathrm{m}$. Images were acquired using an upright LEICA TCS SP2 confocal microscope (Leica Microsystems, Heidelberg, Germany) with an HVX PL APO 63× NA 1.4 oil immersion objective. Image processing and spine classification were performed as previously described. ${ }^{83}$

Statistical Analysis. Statistical significance was determined by one-way ANOVA followed by Dunnett's test, independent $t$-test, or by one sample $t$-test. Data were analyzed using SYSTAT 10 (SPSS).

\section{ASSOCIATED CONTENT}

\section{Supporting Information}

The Supporting Information is available free of charge on the ACS Publications website at DOI: 10.1021/acsomega.8b02311. 
Methods section for the synthesis of triblock copolymer and the $\mathrm{AF}_{4}$ methodology; schematic representation for the synthesis of PMOXA-PDMS-PMOXA; $\mathrm{H}^{1}$ NMR and ${ }^{19} \mathrm{~F}$ NMR charts of PMOXA-PDMS-PMOXA; calibration curve for BSA and curcumin-loaded polymersomes; hydrodynamic radius distributions of polymersomes prepared by the rehydration method determined by DLS; kinetics of the release of curcumin and NGF from PMOXA-PDMS-PMOXA triblock-based polymersomes; $\mathrm{AF}_{4}$ fractograms of PMOXA-PDMSPMOXA-based polymersomes loaded with NGF-rhodamine and functionalized with memantine and TZG; $\mathrm{AF}_{4}$ calibration of NGF alone; electron micrographs of polymersomes; fluorescent micrographs of primary dissociated DRG cultures exposed to RhB-labeled polymersomes containing NGF; and image transformation for measurement of the neurite surface area using Image s software (PDF)

\section{AUTHOR INFORMATION}

\section{Corresponding Author}

*E-mail: dusica.maysinger@mcgill.ca (D.M.).

\section{ORCID $\odot$}

Françoise M. Winnik: 0000-0001-5844-6687

Dusica Maysinger: 0000-0002-0017-5201

\section{Author Contributions}

A.M. and J.J. participated equally in this work. The manuscript was written through contributions of all authors. All authors have given approval to the final version of the manuscript.

\section{Funding}

This work was supported by a grant from Natural Sciences and Engineering Council of Canada (F.M.W. and D.M.) and Canadian Institutes for Health Research (CIHR) to D.M.

\section{Notes}

The authors declare no competing financial interest.

\section{ACKNOWLEDGMENTS}

We would like to thank Dr. Carlos Agudelo for the preparation of polymersomes. We thank Dr. RA McKinney for providing transgenic animals and François Charon for preparation of the organotypic slice cultures. We thank Dr. Anie Philip for providing recombinant CD109 protein. DM thanks the Canadian Institute for Health Research (MOP-11945) and the Natural Sciences and Engineering Council of Canada (RGPIN 04994-15). We would like to thank the Facility for electron research (FEMR) of McGill University for providing access to the T12 electron microscope.

\section{ABBREVIATIONS}

$\mathrm{AF}_{4}$, asymmetrical flow field-flow fractionation; ANOVA, analysis of variance; BSA, bovine serum albumin; DAPI, $4^{\prime}, 6-$ diamidino-2-phenylindole; DMEM, Dulbecco's modified Eagle's medium; DMSO, dimethyl sulfoxide; DRG, dorsal root ganglia; FGF, fibroblast growth factor; HBSS, Hank's balanced salts solution; MALS, multiangle light scattering; MAPK/ERK, mitogen-activated protein kinase/extracellular signal-regulated kinase; MitC, mitomycin C; MTT, 3-(4,5dimethylthiazol-2-yl)-2,5-diphenyltetrazolium bromide; MWCO, molecular weight cutoff; NGF, nerve growth factor; NMR, nuclear magnetic resonance; PBS, phosphate-buffered saline; PDMS, poly(dimethylsiloxane); PI3K, phosphoinosi- tide 3-kinase; PMOXA, poly(2-methyl-2-oxazoline); RT, room temperature; SEM, standard error of the mean; TZG, $R, S$ tetrazolylglycine

\section{REFERENCES}

(1) Finetti, F.; Baldari, C. T. Compartmentalization of signaling by vesicular trafficking: a shared building design for the immune synapse and the primary cilium. Immunol. Rev. 2013, 251, 97-112.

(2) Leitman, J.; Ron, E.; Ogen-Shtern, N.; Lederkremer, G. Z. Compartmentalization of endoplasmic reticulum quality control and ER-associated degradation factors. DNA Cell Biol. 2013, 32, 2-7.

(3) Chahar, H.; Bao, X.; Casola, A. Exosomes and Their Role in the Life Cycle and Pathogenesis of RNA Viruses. Viruses 2015, 7, 32043225 .

(4) Sampey, G. C.; Meyering, S. S.; Asad Zadeh, M.; Saifuddin, M.; Hakami, R. M.; Kashanchi, F. Exosomes and their role in CNS viral infections. J. Neurovirol. 2014, 20, 199-208.

(5) Saman, S.; Lee, N. C. Y.; Inoyo, I.; Jin, J.; Li, Z.; Doyle, T.; McKee, A. C.; Hall, G. F. Proteins recruited to exosomes by tau overexpression implicate novel cellular mechanisms linking tau secretion with Alzheimer's disease. J. Alzheimer's Dis. 2014, 40, S47-S70.

(6) Toffoli, G.; Hadla, M.; Corona, G.; Caligiuri, I.; Palazzolo, S.; Semeraro, S.; Gamini, A.; Canzonieri, V.; Rizzolio, F. Exosomal doxorubicin reduces the cardiac toxicity of doxorubicin. Nanomedicine 2015, 40, S47-S70.

(7) Saari, H.; Lazaro-Ibanez, E.; Viitala, T.; Vuorimaa-Laukkanen, E.; Siljander, P.; Yliperttula, M. Microvesicle- and exosome-mediated drug delivery enhances the cytotoxicity of Paclitaxel in autologous prostate cancer cells. J. Controlled Release 2015, 10, 2963-2971.

(8) Tran, T.-H.; Mattheolabakis, G.; Aldawsari, H.; Amiji, M. Exosomes as nanocarriers for immunotherapy of cancer and inflammatory diseases. Clin. Immunol. 2015, 160, 46-58.

(9) Müller, L. K.; Landfester, K. Natural liposomes and synthetic polymeric structures for biomedical applications. Biochem. Biophys. Res. Commun. 2015, 468, 411-418.

(10) Onaca, O.; Enea, R.; Hughes, D. W.; Meier, W. Stimuliresponsive polymersomes as nanocarriers for drug and gene delivery. Macromol. Biosci. 2009, 9, 129-139.

(11) Guan, L.; Rizzello, L.; Battaglia, G. Polymersomes and their applications in cancer delivery and therapy. Nanomedicine 2015, 10, 2757-2780.

(12) Oltra, N. S.; Nair, P.; Discher, D. E. From Stealthy Polymersomes and Filomicelles to "Self" Peptide-Nanoparticles for Cancer Therapy. Annu. Rev. Chem. Biomol. Eng. 2014, 5, 281-299.

(13) Zhao, L.; Li, N.; Wang, K.; Shi, C.; Zhang, L.; Luan, Y. A review of polypeptide-based polymersomes. Biomaterials 2014, 35, 12841301.

(14) Song, J.; Huang, P.; Duan, H.; Chen, X. Plasmonic Vesicles of Amphiphilic Nanocrystals: Optically Active Multifunctional Platform for Cancer Diagnosis and Therapy. Acc. Chem. Res. 2015, 48, 25062515.

(15) Le Meins, J.-F.; Sandre, O.; Lecommandoux, S. Recent trends in the tuning of polymersomes' membrane properties. Eur. Phys. J. E: Soft Matter Biol. Phys. 2011, 34, 14.

(16) Upadhyay, K. K.; Bhatt, A. N.; Castro, E.; Mishra, A. K.; Chuttani, K.; Dwarakanath, B. S.; Schatz, C.; Le Meins, J.-F.; Misra, A.; Lecommandoux, S. In vitro and in vivo evaluation of docetaxel loaded biodegradable polymersomes. Macromol. Biosci. 2010, 10, 503-512.

(17) Ayen, W. Y.; Kumar, N. In Vivo Evaluation of DoxorubicinLoaded (PEG)3-PLA Nanopolymersomes (PolyDoxSome) Using DMBA-Induced Mammary Carcinoma Rat Model and Comparison with Marketed LipoDox. Pharm. Res. 2012, 29, 2522-2533.

(18) Ahmed, F.; Pakunlu, R. I.; Brannan, A.; Bates, F.; Minko, T.; Discher, D. E. Biodegradable polymersomes loaded with both paclitaxel and doxorubicin permeate and shrink tumors, inducing 
apoptosis in proportion to accumulated drug. J. Controlled Release 2006, 116, 150-158.

(19) Zou, T.; Dembele, F.; Beugnet, A.; Sengmanivong, L.; Trepout, S.; Marco, S.; de Marco, A.; Li, M.-H. Nanobody-functionalized PEGb-PCL polymersomes and their targeting study. J. Biotechnol. 2015, 214, 147-155.

(20) Yildirim, T.; Traeger, A.; Sungur, P.; Hoeppener, S.; Kellner, C.; Yildirim, I.; Pretzel, D.; Schubert, S.; Schubert, U. S. Polymersomes with Endosomal pH-Induced Vesicle-to-Micelle Morphology Transition and a Potential Application for Controlled Doxorubicin Delivery. Biomacromolecules 2017, 18, 3280-3290.

(21) Morimoto, N.; Sasaki, Y.; Mitsunushi, K.; Korchagina, E.; Wazawa, T.; Qiu, X.-P.; Nomura, S.-i. M.; Suzuki, M.; Winnik, F. M. Temperature-responsive telechelic dipalmitoylglyceryl poly (N-isopropylacrylamide) vesicles: real-time morphology observation in aqueous suspension and in the presence of giant liposomes. Chem. Commun. 2014, 50, 8350-8352.

(22) De Oliveira, H.; Thevenot, J.; Lecommandoux, S. Smart polymersomes for therapy and diagnosis: fast progress toward multifunctional biomimetic nanomedicines. Wiley Interdiscip. Rev.: Nanomed. Nanobiotechnol. 2012, 4, 525-546.

(23) Meng, F.; Zhong, Z.; Feijen, J. Stimuli-Responsive Polymersomes for Programmed Drug Delivery. Biomacromolecules 2009, 10, 197-209.

(24) Anajafi, T.; Yu, J.; Sedigh, A.; Haldar, M. K.; Muhonen, W. W.; Oberlander, S.; Wasness, H.; Froberg, J.; Molla, M. D. S.; Katti, K. S.; Choi, Y.; Shabb, J. B.; Srivastava, D. K.; Mallik, S. Nuclear Localizing Peptide-Conjugated, Redox-Sensitive Polymersomes for Delivering Curcumin and Doxorubicin to Pancreatic Cancer Microtumors. Mol. Pharm. 2017, 14, 1916-1928.

(25) Christian, D. A.; Cai, S.; Bowen, D. M.; Kim, Y.; Pajerowski, J. D.; Discher, D. E. Polymersome carriers: From self-assembly to siRNA and protein therapeutics. Eur. J. Pharm. Biopharm. 2009, 71, 463-474.

(26) Nardin, C.; Hirt, T.; Leukel, J.; Meier, W. Polymerized ABA triblock copolymer vesicles. Langmuir 2000, 16, 1035-1041.

(27) Bai, L.; Tan, L.; Chen, L.; Liu, S.; Wang, Y. Preparation and characterizations of poly(2-methyl-2-oxazoline) based antifouling coating by thermally induced immobilization. J. Mater. Chem. B 2014, 2, 7785-7794.

(28) Zheng, X.; Zhang, C.; Bai, L.; Liu, S.; Tan, L.; Wang, Y. Antifouling property of monothiol-terminated bottle-brush poly(methylacrylic acid)-graft-poly(2-methyl-2-oxazoline) copolymer on gold surfaces. J. Mater. Chem. B 2015, 3, 1921-1930.

(29) Chen, Y.; Cao, W.; Zhou, J.; Pidhatika, B.; Xiong, B.; Huang, L.; Tian, Q.; Shu, Y.; Wen, W.; Hsing, I.-M.; Wu, H. Poly(l-lysine)graft-folic acid-coupled poly(2-methyl-2-oxazoline) (PLL-g-PMOXAc-FA): A Bioactive Copolymer for Specific Targeting to Folate Receptor-Positive Cancer Cells. ACS Appl. Mater. Interfaces 2015, 7, 2919-2930.

(30) Tam, J.; Rosenberg, L.; Maysinger, D. Islet-neogenesisassociated protein enhances neurite outgrowth from DRG neurons. Biochem. Biophys. Res. Commun. 2002, 291, 649-654.

(31) Boateng, J. S.; Matthews, K. H.; Stevens, H. N. E.; Eccleston, G. M. Wound healing dressings and drug delivery systems: a review. J. Pharm. Sci. 2008, 97, 2892-2923.

(32) Velnar, T.; Bailey, T.; Smrkolj, V. The Wound Healing Process: An Overview of the Cellular and Molecular Mechanisms. J. Int. Med. Res. 2009, 37, 1528-1542.

(33) Demidova-Rice, T. N.; Hamblin, M. R.; Herman, I. M. Acute and Impaired Wound Healing. Adv. Skin Wound Care 2012, 25, 304314.

(34) Gantwerker, E. A.; Hom, D. B. Skin: histology and physiology of wound healing. Clin. Plast. Surg. 2012, 39, 85-97.

(35) Geronemus, R. G.; Mertz, P. M.; Eaglstein, W. H. Wound Healing. Arch. Dermatol. 1979, 115, 1311-1314.

(36) Kjolseth, D.; Frank, J. M.; Barker, J. H.; Anderson, G. L.; Rosenthal, A. I.; Acland, R. D.; Schuschke, D.; Campbell, F. R.; Tobin, G. R.; Weiner, L. J. Comparison of the effects of commonly used wound agents on epithelialization and neovascularization. J. Am. Coll. Surg. 1994, 179, 305-312.

(37) Micera, A.; Vigneti, E.; Pickholtz, D.; Reich, R.; Pappo, O.; Bonini, S.; Maquart, F. X.; Aloe, L.; Levi-Schaffer, F. Nerve growth factor displays stimulatory effects on human skin and lung fibroblasts, demonstrating a direct role for this factor in tissue repair. Proc. Natl. Acad. Sci. U.S.A. 2001, 98, 6162-6167.

(38) Hermes, B.; Welker, P.; Feldmann-Böddeker, I.; KrügerKrasagakis, S.; Hartmann, K.; Zuberbier, T.; Henz, B. M. Expression of mast cell growth modulating and chemotactic factors and their receptors in human cutaneous scars. J. Invest. Dermatol. 2001, 116, 387-393.

(39) Hefti, F. Nerve growth factor promotes survival of septal cholinergic neurons after fimbrial transections. J. Neurosci. 1986, 6, 2155-2162.

(40) Ginty, D.; Segal, R. A. Retrograde neurotrophin signaling: Trking along the axon. Curr. Opin. Neurobiol. 2002, 12, 268-274.

(41) Indwelling Neural Implants: Strategies for Contending with the In Vivo Environment; Reichert, W. M., Ed.; CRC Press/Taylor \& Francis Taylor \& Francis Group, LLC.: Boca Raton (FL), 2008.

(42) Elkabes, S.; DiCicco-Bloom, E. M.; Black, I. B. Brain microglia/ macrophages express neurotrophins that selectively regulate microglial proliferation and function. J. Neurosci. 1996, 16, 2508-2521.

(43) Nakajima, K.; Honda, S.; Tohyama, Y.; Imai, Y.; Kohsaka, S.; Kurihara, T. Neurotrophin secretion from cultured microglia. J. Neurosci. Res. 2001, 65, 322-331.

(44) Yallapu, M. M.; Nagesh, P. K. B.; Jaggi, M.; Chauhan, S. C. Therapeutic Applications of Curcumin Nanoformulations. AAPS J. 2015, 17, 1341-1356.

(45) Kulac, M.; Aktas, C.; Tulubas, F.; Uygur, R.; Kanter, M.; Erboga, M.; Ceber, M.; Topcu, B.; Ozen, O. A. The effects of topical treatment with curcumin on burn wound healing in rats. J. Mol. Histol. 2013, 44, 83-90.

(46) Akbik, D.; Ghadiri, M.; Chrzanowski, W.; Rohanizadeh, R. Curcumin as a wound healing agent. Life Sci. 2014, 116, 1-7.

(47) Krausz, A. E.; Adler, B. L.; Cabral, V.; Navati, M.; Doerner, J.; Charafeddine, R. A.; Chandra, D.; Liang, H.; Gunther, L.; Clendaniel, A.; Harper, S.; Friedman, J. M.; Nosanchuk, J. D.; Friedman, A. J. Curcumin-encapsulated nanoparticles as innovative antimicrobial and wound healing agent. Nanomedicine 2015, 11, 195-206.

(48) Vorstenbosch, J.; Nguyen, C. M.; Zhou, S.; Seo, Y. J.; Siblini, A.; Finnson, K. W.; Bizet, A. A.; Tran, S. D.; Philip, A. Overexpression of CD109 in the Epidermis Differentially Regulates ALK1 Versus ALK5 Signaling and Modulates Extracellular Matrix Synthesis in the Skin. J. Invest. Dermatol. 2017, 137, 641-649.

(49) Li, C.; Hancock, M. A.; Sehgal, P.; Zhou, S.; Reinhardt, D. P.; Philip, A. Soluble CD109 binds TGF- and antagonizes TGFsignalling and responses. Biochem. J. 2016, 473, 537.

(50) Bizet, A. A.; Liu, K.; Tran-Khanh, N.; Saksena, A.; Vorstenbosch, J.; Finnson, K. W.; Buschmann, M. D.; Philip, A. The TGF- $\beta$ co-receptor, CD109, promotes internalization and degradation of TGF- $\beta$ receptors. Biochim. Biophys. Acta 2011, 1813, $742-753$.

(51) Finnson, K. W.; Tam, B. Y. Y.; Liu, K.; Marcoux, A.; Lepage, P.; Roy, S.; Bizet, A. A.; Philip, A. Identification of CD109 as part of the TGF- $\beta$ receptor system in human keratinocytes. Faseb. J. 2006, 20, $1525-1527$.

(52) Mondal, S.; Ghosh, S.; Moulik, S. P. Stability of curcumin in different solvent and solution media: UV-visible and steady-state fluorescence spectral study. J. Photochem. Photobiol., B 2016, 158, $212-218$.

(53) Zhu, G.; Mallery, S. R.; Schwendeman, S. P. Stabilization of proteins encapsulated in injectable poly (lactide- co-glycolide). Nat. Biotechnol. 2000, 18, 52-57.

(54) Lee, J. S.; Feijen, J. Polymersomes for drug delivery: design, formation and characterization. J. Controlled Release 2012, 161, 473483.

(55) Kempe, K.; Vollrath, A.; Schaefer, H. W.; Poehlmann, T. G.; Biskup, C.; Hoogenboom, R.; Hornig, S.; Schubert, U. S. Multifunc- 
tional Poly(2-oxazoline) Nanoparticles for Biological Applications. Macromol. Rapid Commun. 2010, 31, 1869-1873.

(56) Bocchini, V. The Nerve Growth Factor. Amino Acid Composition and Physicochemical Properties. Eur. J. Biochem. 1970, 15, 127-131.

(57) Medda, L.; Monduzzi, M.; Salis, A. The molecular motion of bovine serum albumin under physiological conditions is ion specific. Chem. Commun. 2015, 51, 6663-6666.

(58) Ma, P. L.; Buschmann, M. D.; Winnik, F. M. One-step analysis of DNA/chitosan complexes by field-flow fractionation reveals particle size and free chitosan content. Biomacromolecules 2010, 11, 549-554.

(59) Diamond, J.; Holmes, M.; Coughlin, M. Endogenous NGF and nerve impulses regulate the collateral sprouting of sensory axons in the skin of the adult rat. J. Neurosci. 1992, 12, 1454-1466.

(60) Kawamoto, K.; Matsuda, H. Nerve growth factor and wound healing. Prog. Brain Res. 2004, 146, 369-384.

(61) Fang, Y.; Eglen, R. M. Three-Dimensional Cell Cultures in Drug Discovery and Development. SLAS Discovery 2017, 22, 456472.

(62) Pampaloni, F.; Reynaud, E. G.; Stelzer, E. H. K. The third dimension bridges the gap between cell culture and live tissue. Nat. Rev. Mol. Cell Biol. 2007, 8, 839-845.

(63) Paşca, S. P. The rise of three-dimensional human brain cultures. Nature 2018, 553, 437.

(64) Waterhouse, E. G.; Xu, B. New insights into the role of brainderived neurotrophic factor in synaptic plasticity. Mol. Cell. Neurosci. 2009, 42, 81-89.

(65) Griesbach, G. S.; Hovda, D. A.; Molteni, R.; Wu, A.; GomezPinilla, F. Voluntary exercise following traumatic brain injury: brainderived neurotrophic factor upregulation and recovery of function. Neuroscience 2004, 125, 129-139.

(66) Wang, L.; Zhang, Z.; Wang, Y.; Zhang, R.; Chopp, M. Treatment of Stroke With Erythropoietin Enhances Neurogenesis and Angiogenesis and Improves Neurological Function in Rats. Stroke 2004, 35, 1732-1737.

(67) Chen, J.; Zhang, C.; Jiang, H.; Li, Y.; Zhang, L.; Robin, A.; Katakowski, M.; Lu, M.; Chopp, M. Atorvastatin Induction of VEGF and BDNF Promotes Brain Plasticity after Stroke in Mice. J. Cerebr. Blood Flow Metabol. 2005, 25, 281-290.

(68) Sakane, T.; Pardridge, W. M. Carboxyl-directed pegylation of brain-derived neurotrophic factor markedly reduces systemic clearance with minimal loss of biologic activity. Pharm. Res. 1997, 14, 1085-1091.

(69) Leal, G.; Afonso, P. M.; Salazar, I. L.; Duarte, C. B. Regulation of hippocampal synaptic plasticity by BDNF. Brain Res. 2015, 1621, $82-101$.

(70) Calfa, G.; Chapleau, C. A.; Campbell, S.; Inoue, T.; Morse, S. J.; Lubin, F. D.; Pozzo-Miller, L. HDAC activity is required for BDNF to increase quantal neurotransmitter release and dendritic spine density in CA1 pyramidal neurons. Hippocampus 2012, 22, 1493-1500.

(71) Tyler, W. J.; Pozzo-Miller, L. Miniature synaptic transmission and BDNF modulate dendritic spine growth and form in rat CA1 neurones. J. Physiol. 2003, 553, 497-509.

(72) Lu, B.; Nagappan, G.; Lu, Y. BDNF and synaptic plasticity, cognitive function, and dysfunction. Handb. Exp. Pharmacol. 2014, 220, 223-250.

(73) Gao, X.; Chen, J. Mild traumatic brain injury results in extensive neuronal degeneration in the cerebral cortex. J. Neuropathol. Exp. Neurol. 2011, 70, 183-191.

(74) Aungst, S. L.; Kabadi, S. V.; Thompson, S. M.; Stoica, B. A.; Faden, A. I. Repeated mild traumatic brain injury causes chronic neuroinflammation, changes in hippocampal synaptic plasticity, and associated cognitive deficits. J. Cereb. Blood Flow Metab. 2014, 34, $1223-1232$.

(75) Lau, C. G.; Zukin, R. S. NMDA receptor trafficking in synaptic plasticity and neuropsychiatric disorders. Nat. Rev. Neurosci. 2007, 8, 413-426.
(76) Malenka, R. C.; Nicoll, R. A. NMDA-receptor-dependent synaptic plasticity: multiple forms and mechanisms. Trends Neurosci. 1993, 16, 521-527.

(77) Johnson, J.; Kotermanski, S. Mechanism of action of memantine. Curr. Opin. Pharmacol. 2006, 6, 61-67.

(78) Cummings, K. A.; Popescu, G. K. Glycine-dependent activation of NMDA receptors. J. Gen. Physiol. 2015, 145, 513-527.

(79) Savchenko, A.; Braun, G. B.; Molokanova, E. Nanostructured Antagonist of Extrasynaptic NMDA Receptors. Nano Lett. 2016, 16, $5495-5502$

(80) Stoenescu, R.; Graff, A.; Meier, W. Asymmetric ABC-triblock copolymer membranes induce a directed insertion of membrane proteins. Macromol. Biosci. 2004, 4, 930-935.

(81) Meijering, E.; Jacob, M.; Sarria, J.-C. F.; Steiner, P.; Hirling, H.; Unser, M. Design and validation of a tool for neurite tracing and analysis in fluorescence microscopy images. Cytometry, Part A 2004, $58,167-176$.

(82) Gähwiler, B.; Capogna, M.; Debanne, D.; McKinney, R. A.; Thompson, S. M. Organotypic slice cultures: a technique has come of age. Trends Neurosci. 1997, 20, 471-477.

(83) Maysinger, D.; Ji, J.; Moquin, A.; Hossain, S.; Hancock, M. A.; Zhang, I.; Chang, P. K. Y.; Rigby, M.; Anthonisen, M.; Grütter, P.; Breitner, J.; McKinney, R. A.; Reimann, S.; Haag, R.; Multhaup, G. Dendritic Polyglycerol Sulfates in the Prevention of Synaptic Loss and Mechanism of Action on Glia. ACS Chem. Neurosci. 2018, 9, 260271. 